\title{
Dr. Luis Alejandro Pachón Cárdenas
}

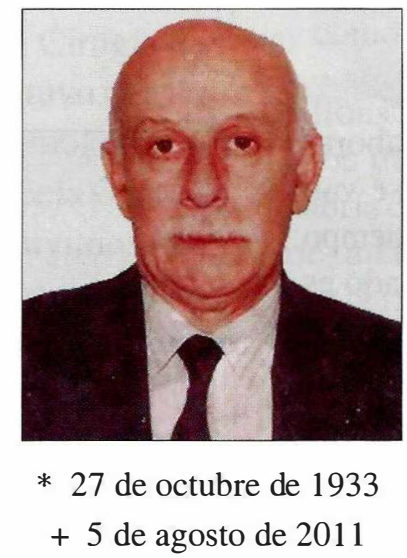

El Departamento de Ginecología y Obstetricia lamenta el fallecimiento del doctor Luis Alejandro Pachón Cárdenas, profesor titular de ginecología y obstetricia en el área de colposcopia y patología del tracto genital inferior. Egresado de la Facultad de Medicina de Buenos Aires, Argentina, en 1959; se constituyó como médico ginecólogo autorizado para colposcopia en 1976. Sus comienzos como ginecoobstetra en Colombia están descritos en 1979 donde participa como fundador de la unidad de patología cervical y colposcopia del Hospital de San José. Posteriormente, en 1983 fue promotor y miembro fundador de la Sociedad Colombiana de Patología Cervical y Colposcopia, de la que fue presidente honorario en 2000.

Desde su llegada a Colombia su gestión más importante era realizar una campaña de enseñanza y difusión de la colposcopia, prevención y diagnóstico precoz del cáncer de cérvix en nuestro país. El doctor Pachón siempre se caracterizó por su dedicación y entrega al conocimiento en esta área de la ginecología, presentó innumerables trabajos y publicaciones los cuales lo hicieron merecedor de grandes reconocimientos nacionales e internacionales. Fue miembro honorario de reconocidas sociedades científicas entre ellas:

Sociedad de Geriatría y Gerontología en México 1980.

Asociación Antioqueña de Obstetricia y Ginecología en 1982.

Sociedad Argentina de Patología Cervical Uterina y Colposcopia en 1986.

Sociedad Colombiana de Obstetricia y Ginecología en 1984.

Sociedad de Obstetricia y Ginecología del Atlántico en 1988.

Director Honorario de la unidad de Patología Cervical y Colposcopia de la Liga Colombiana de Lucha Contra el Cáncer en 1983.

Asociación Colombiana de Menopausia en 1995.

Además, diseñó y fabricó el primer colposcopio de producción nacional.

En 1998 fue nombrado Profesor Titular de la cátcdra de obstctricia y ginecología de la Fundación Universitaria de Ciencias de la Salud, Hospital de San José, labor que desempeñó con esmero y dedicación llegando a obtener en 2007 uno de sus principales nombramientos el cual fue motivo de orgullo y satisfacción personal, como maestro latinoamericano de colposcopia.

Los que tuvimos la dicha de que fuera nuestro maestro y amigo, no tenemos palabras para expresar nuestro cariño y admiración por él. Aquí quedan sus vivencias, enseñanzas e impulso siempre dinámico y responsable.

El Hospital de San José y la Fundación Universitaria de Ciencias de la Salud pierden a un gran profesional y docente de muchas generaciones. 